\title{
PROPONDO CAMINHOS PARA O LETRAMENTO VISUAL: UMA LEITURA SEM IÓTICA DO LIVRO DE IMAGENS CENA DE RUA
}

Eduardo Lopes Piris ${ }^{1}$

\begin{abstract}
Resumo: Este trabalho visa a oferecer uma proposta de leitura de narrativas visuais aos professores de Artes e de Línguas. Para tanto, apresenta uma análise semiótica do livro de imagens intitulado Cena de Rua de autoria de Angela Lago (1994). Discute alguns problemas em torno do letramento visual no contexto escolar. Delineia um panorama do realismo crítico na literatura infantil e juvenil a fim de mostrar o contexto sócio-histórico por meio do qual emerge o discurso desse livro de imagens. Analisa a expressão e o conteúdo das imagens, examinando alguns elementos dos níveis narrativo e discursivo do percurso gerativo de sentido para depreender seu sentido.

Palavras-Chave: Letramento visual, Semiótica, Literatura infanto-juvenil, Narrativa visual.
\end{abstract}

\begin{abstract}
The aim of this work is to offer a proposal for reading visual narratives to teachers of arts and languages. To this end, it presents a semiotic analysis of the book of images entitled Cena da Rua by Angela Lago (1994). It discusses certain problems concerning visual literacy in the context of schooling. It outlines a panorama of critical realism in children's and young people's literature to show the socio-historic context through which emerges the discourse of this book of images. It analyses the expression and the content of the images, examining certain elements of the narrative and discursive levels of the generative process of meaning.

Key Words: Visual literacy, Children's literature, Semiotics, Visual narrative.
\end{abstract}

\section{INTRODUÇÃO}

Uma observação inicial: apesar de ser recente a discussão sobre a relação entre a escola e as novas mídias, os objetos de estudo não o são. Se o meio de expressão visual acompanha o homem desde as suas primeiras inscrições rupestres, a instituição escolar privilegia, desde muito tempo, a exegese do texto verbal, primeiro o oral (com o surgimento da retórica) e depois o escrito (com o advento da imprensa).

Trazendo a questão para o nosso contexto brasileiro, embora os Parâmetros Curriculares Nacionais (BRASIL, 1998, p. 2000) façam menção à importância da linguagem não-verbal e às novas tecnologias de informação, presenciamos ainda em nossas escolas o que Adilson Citelli (2004, p. 21) chama de descompasso:

1 Professor de Língua Portuguesa da Faculdade Montessori de Ibiúna; doutorando em Língua Portuguesa pelo Departamento de Letras Clássicas e Vernáculas da Universidade de São Paulo - USP. Endereço eletrônico: eduardo_piris@yahoo.com.br. 
Talvez o termo descompasso seja o mais adequado para designar a situação presente vivida pelas escolas dos ciclos fundamental e médio diante dos meios de comunicação e das novas tecnologias. As pesquisas que realizamos [...] revelam 0 profundo desencontro entre o discurso didático-pedagógico estrito e as linguagens institucionalmente não-escolares (CITELLI, 2004, p. 21).

Seria óbvio afirmar que esse descompasso se deve à disparidade que há entre a velocidade em que ocorrem as mudanças nos meios de comunicação e na instituição escolar; às redes de ensino que não capacitam adequadamente seus professores; às instituições de ensino superior que não contemplam as novas linguagens em seus cursos de Pedagogia, de Letras e de Artes; aos cursos de pós-graduação - oferecidos por essas mesmas instituições de ensino que negligenciam tais linguagens preocupando-se em suprir supostas carências do professor em sua formação inicial; à boa parte da pesquisa desenvolvida por nossas universidades em que uma determinada área do conhecimento se especializa sobremaneira no que entende ser o seu domínio que chega a desconsiderar o que uma área afim está explorando, tal como ocorre em Letras e em Artes.

É por essa razão que Citelli afirma que "há que se combinar pesquisa, reflexão e ação, num movimento cujo resultado retorne o mais rapidamente possível ao espaço escolar" (CITELLI, 2004, p. 31). Para nós, esse resultado pode ser alcançado por meio de uma postura interdisciplinar no âmbito da pesquisa e da prática pedagógica. E essa é a pretensão deste trabalho, que ao assumir os pressupostos teóricos da Semiótica greimasiana - visa a apresentar uma proposta de leitura de narrativa visual voltada para a prática pedagógica tanto na área de Artes como na de Letras.

\section{LETRAMENTO VISUAL}

Dondis $(2004)^{2}$ apresenta a questão do alfabetismo visual, enfatizando a necessidade de um olhar objetivo e metodológico sobre a linguagem visual:

Dentre todos os meios de comunicação humana, o visual é o único que não dispõe de um conjunto de normas e preceitos, de metodologia e de nem um único sistema com critérios definidos, tanto para a expressão quanto para o entendimento dos métodos visuais. [...]. Não resta dúvida de que se torna imperativa uma nova abordagem que possa solucionar esse dilema (DONDIS, 2004, p. 18).

É preciso destacar que essa abordagem proposta por Dondis (2004, p. 30-31) está fortemente ancorada no fator psicofisiológico. A autora entende que a comunicação da mensagem visual é a manifestação verdadeira do artis-

2 Obra publicada originalmente em 1973 pelo MIT - The Massachusetts Institute of Technology - com o título A Primer of Visual Literacy. 
ta, ao passo que sua recepção depende da resposta subjetiva do espectador, atribuindo, única e exclusivamente, ao aparelho sensorial da visão a condição de comunicação entre artista e público:

Um só fator é moeda corrente entre 0 artista e o público, e, na verdade, entre todas as pessoas - o sistema físico das percepções visuais, os componentes psicofisiológicos do sistema nervoso, o funcionamento mecânico, o aparato sensorial através do qual vemos (DONDIS, 2004, p. 31).

De fato, a leitura de imagens que não se pretende subjetiva necessita de aparato teórico, de instrumentos que a tornem mais objetiva. Todavia, acreditamos que qualquer objeto construído por meio da linguagem visual é inexoravelmente concebido no seio de uma cultura, emergido de um contexto sóciohistórico, o que lhe confere o estatuto de enunciado, de enunciado visual. Assim, respaldados por nossas considerações preliminares, acreditamos que, embora não seja possível negar a dimensão psicofisiológica que envolve o objeto visual, não devemos tê-la como o único nem o mais importante fator de existência de tal objeto, sob o risco de incorporarmos concepções meramente mecanicistas às nossas práticas pedagógicas.

Dondis ainda relativiza a importância dos fenômenos psicofisiológicos ao mostrar o que o pensamento da psicologia da Gestalt pode oferecer em termos de análise e compreensão de qualquer sistema:

Grande parte do que sabemos sobre a interação e o efeito da percepção humana sobre o significado visual provém das pesquisas e dos experimentos da psicologia da Gestalt, mas o pensamento gestaltista tem mais a oferecer além da mera relação entre fenômenos psicofisiológicos e expressão visual. Sua base teórica é a crença em que uma abordagem da compreensão e da análise de todos os sistemas exige que se reconheça que o sistema [...] como um todo é formado por partes interatuantes, que podem ser isoladas e vistas como inteiramente independentes, e depois reunidas no todo (DONDIS, 2004, p. 51).

Ora, isso não é concepção teórica, é um método de análise, de estudo de um objeto, que, além de não ser exclusivo da psicologia da Gestalt, tem sua origem no Discurso do método de René Descartes. Mas, se nos afastamos desse ponto de vista adotado por Dondis, acolhemos bem os esforços no sentido de sistematizar uma gramática da linguagem visual que visa a estabelecer os elementos básicos de composição da imagem, os quais serão recuperados em nossa análise. De todo modo, nosso objetivo não é levar a cabo essa discussão, mas apenas deixar uma porta de entrada para reflexões sobre essa questão, pois o que nos interessa, neste momento, é tecer considerações sobre o alfabetismo visual, que preferimos chamar de letramento visual em razão de ser um termo consagrado na bibliografia brasileira. 
Quando lemos "alfabetismo" estamos diante de uma tradução da palavra inglesa literacy, a qual também dá origem ao termo "letramento". As traduções e as revisões da literatura costumam veicular o termo "alfabetismo", ao passo que "letramento" já se consagra na produção intelectual brasileira. Por exemplo, M agda Soares (2008), em seu artigo "Ĺngua escrita, sociedade e cultura: relações, dimensões e perspectivas", de 1995, recorre ao uso do termo "alfabetismo", substituindo-o por "letramento" em suas obras posteriores, como em Letramento: um tema em três gêneros, de 1998. Nesse contexto, não há problema em dizer que os termos "alfabetismo" e "letramento" correspondem ao mesmo fenômeno.

Diferentemente da alfabetização, o alfabetismo (ou letramento) não se encerra na aquisição da tecnologia da leitura e da escrita, mas é a conseqüência de sua incorporação à vida do indivíduo. Nesse sentido, Magda Soares explica que:

Só recentemente esse termo tem sido necessário, porque só recentemente co-
meçamos a enfrentar uma realidade social em que não basta simplesmente "sa-
ber ler e escrever": dos indivíduos já se requer não apenas que dominem a tec-
nologia do ler e do escrever, mas também que saibam fazer uso dela,
incorporando-a a seu viver, transformando-se assim seu "estado" ou "condição",
como conseqüência do domínio dessa tecnologia (SOARES, 2008, p. 29).

Assim, 0 alfabetismo consiste em um conjunto de comportamentos que podem ser agrupados de acordo com duas dimensões: a individual e a social. $\mathrm{Na}$ primeira, destaca-se a posse individual de habilidades de leitura e escrita tais como a habilidade de decodificar símbolos escritos até a habilidade de refletir sobre a importância do que foi lido, passando pelas habilidades de depreender o sentido de um texto, de interpretar seqüências de idéias, de compreender analogias, comparações, linguagem figurada, anáfora (SOARES, 2008, p. 31). Já, do ponto de vista social, o alfabetismo é considerado como um fenômeno cultural, e não um estado ou condição individual, o que "implica em um conjunto de práticas sociais associadas com a leitura e a escrita, efetivamente exercidas pelas pessoas em um contexto social específico" (SOARES, 2008, p. 33).

Essa dimensão social do conceito de alfabetismo se apresenta em duas visões distintas. Há uma perspectiva funcional que traz consigo um valor pragmático ao defender o uso das habilidades de leitura e de escrita como meio de 0 indivíduo participar adequadamente das atividades de seu grupo social: é o que conhecemos por alfabetismo funcional. Por outro lado, há uma outra tendência do alfabetismo que entende que as práticas de leitura e escrita não devem ser neutras, mas sim "reforçar ou questionar valores, tradições, 
padrões de poder presentes no contexto social" (SOARES, 2008, p. 35): trata-se aí de uma perspectiva crítica das práticas sociais de leitura e escrita.

Acreditamos que, após essa breve exposição sobre o conceito de alfabetismo (letramento), poderemos compreender bem a comparação que Dondis (2004) faz entre 0 alfabetismo verbal e 0 alfabetismo visual:

Se a invenção do tipo móvel criou o imperativo de um alfabetismo verbal universal, sem dúvida a invenção da câmera e de todas as suas formas paralelas, que não cessam de se desenvolver, criou, por sua vez, o imperativo do alfabetismo visual universal, uma necessidade que há muito se faz sentir (DONDIS, 2004, p.1).

Percebe-se aí que a autora considera a invenção da máquina como o motor do que ela chama de alfabetismo visual universal. Podemos ter a impressão de que o alfabetismo só passou a ser necessário após a invenção da imprensa, e que antes disso não havia uma tradição literária. Mas o que se quer enfatizar aí é o surgimento de uma nova cultura letrada que se criou com o advento da imprensa, bem como o desenvolvimento de uma nova cultura da imagem que nasceu da invenção da câmera fotográfica, da mesma forma que estamos assistindo atualmente ao surgimento de uma cultura cibernética, propiciada pelas novas tecnologias de informação. Trata-se da disseminação dos suportes dos textos verbais e não-verbais e de seu conseqüente alcance social.

No entanto, se à primeira vista essa comparação entre o alfabetismo verbal e o visual contempla a dimensão cultural, parece-nos que falha ao considerar que o indivíduo alfabetizado é aquele que aprende tão somente os componentes básicos da linguagem escrita, tais como as letras, as palavras, a ortografia, a gramática e a sintaxe, que podem construir um número infinito de expressões:

Dominando a leitura e a escrita, o que se pode expressar com esses poucos elementos e princípios é realmente infinito. Uma vez senhor da técnica, qualquer indivíduo é capaz de produzir não apenas uma infinita variedade de soluções criativas para os problemas da comunicação verbal, mas também um estilo pessoal (DONDIS, 2004, p. 3).

Embora não haja menção em seu texto, a autora se apropria aí de uma concepção gerativista de linguagem, cujo fundador é Noam Chomsky, lingüista ligado ao mesmo instituto de pesquisa de Dondis. Margarida Petter (2003) explica que, para Chomsky, toda língua natural possui um número finito de sons ou letras e, mesmo que as sentenças distintas da língua sejam em número infinito, cada sentença só pode ser representada como uma seqüência finita de sons ou letras (PETTER, 2003, p. 15). Acreditamos que isso também elucida por que Dondis (2004, p. 1) emprega o adjetivo "universal" no sin- 
tagma "alfabetismo verbal universal", pois a chamada Gramática Universal é também um dos postulados da teoria gerativista:

Para Chomsky, portanto, a linguagem é uma capacidade inata e específica da espécie, isto é, transmitida geneticamente e própria da espécie humana. Assim sendo, existem propriedades universais da linguagem, segundo Chomsky e os que compartilham de suas idéias (PETTER, 2003, p. 15).

Dondis (2004) assume essa mesma concepção de linguagem para sustentar a possibilidade da construção de infinitas expressões visuais a partir de um número finito de elementos básicos (ponto, linha, forma, direção, tom, cor, textura, escala, direção e movimento). Longe de negar esse fato e de querer polemizar com a teoria gerativa, que - com todas as suas críticas - influenciou positivamente pesquisas sobre aquisição da linguagem que se mostraram muito profícuas no campo da educação, discordamos da afirmação de Dondis de que "o alfabetismo visual deve operar, de alguma maneira, dentro desses limites" (DONDIS, 2004, p. 3), pois a linguagem não se resume aos níveis fundamentais da língua, há outros níveis que devem ser levados em conta ao se abordar a interação humana. Da mesma forma que a leitura de um texto verbal literário não se basta ao exame estilístico de seus elementos fonéticos (assonância, aliteração, rima etc.), morfológicos (prefixação, sufixação, neologismos, seleção lexical etc.) e sintáticos (elipse, paralelismo, inversão e outras construções sintáticas), a leitura de um texto visual artístico não deve também operar somente dentro desses limites. 0 alfabetismo (letramento) pressupõe, no mínimo, a abrangência dos níveis semântico, pragmático e discursivo da linguagem.

Por fim, inclinamo-nos a um letramento que contempla as práticas sociais de leitura e escrita que visam à postura crítica diante dos valores veiculados pelos objetos culturais construídos pelos mais variados meios de expressão. $E$ nossa proposta de letramento visual não é diferente disso. Dentre algumas teorias que podem dar conta desse tipo de objeto cultural e de comunicação, assumiremos neste artigo os pressupostos teóricos da Semiótica greimasiana, pois se coloca como uma teoria que procura entender o texto (em seu sentido largo) por meio do "exame tanto dos mecanismos internos quanto dos fatores contextuais ou sócio-históricos de fabricação do sentido" (BARROS, 2000, p. 8), abarcando não só o texto verbal - escrito ou oral -, mas também os textos visuais, gestuais, sincréticos (com mais de um meio de expressão). 


\section{Panorama do Realsmo Crítico na Lteratura Infanto-Juvenil: Contexto Sócio- HISTÓRICO dE CENA DE RUA}

A biologia foi a ciência que mais se destacou na segunda metade do século XIX. Em 1859, Charles Darwin publicou A origem das espécies e, em 1861, Louis Pasteur e Robert Koch desenvolveram a teoria da microbacteriologia. Esse avanço científico foi um dos fatores determinantes para a alteração do pensamento e do comportamento naquele período, inclusive na literatura, cujo movimento predominante era o Romantismo. Assim, uma nova maneira de ver e de retratar o homem e seus conflitos por meio da narrativa fez-se valer naquele momento: o Naturalismo.

As novas teorias científicas e seus impactos sociais, culturais e literários foram "exportados" para outros países. E, da França para o mundo, a nova tendência foi sendo desdobrada, reelaborada e apropriada conforme a cultura regional. 0 naturalismo francês de Émile Zola desdobra-se no realismo de Flaubert, no inglês Dickens, nos russos Dostoiévski e Tolstói, no português Eça de Queirós, no brasileiro Machado de Assis e entre outros. Se a maneira naturalista de narrar teve sua importância ao romper com a maneira romântica e abrir caminho para novas experiências, os contrastes sociais e os dramas pessoais apenas encontraram seu lugar no Realismo.

Nesse contexto de injustiças sociais, a pobreza assolava a infância na Europa industrializada do século XIX. A criança pobre não era criança, pois não era criada, não brincava, não tinha saúde, enfim, não podia ser feliz, porque estava submetida a aproximadamente dez horas de trabalho em uma fábrica.

Enquanto isso, a literatura retratava seus heróis de maneira avessa à realidade dessas crianças: eles não sofriam como elas, e a narrativa ainda se apresentava num tom moralizador. Naquele momento, se impôs a necessidade de produzir uma literatura mais crítica e denunciativa do que aquela que se fazia. Desse modo, o realismo foi construído, entre outros, por Dickens com Oliver Twist de 1838, Mark Twain com Tom Sawyer de 1871, Hector Malot com Sem família de 1878 e outras obras para a juventude até 1930. No Brasil, após a Semana de 22, Graciliano Ramos retoma o realismo brasileiro de Lima Barreto e Graça Aranha com uma forma reestilizada de narrar o cotidiano, tornando-se o principal escritor brasileiro engajado ao realismo crítico. Destaca-se ainda a obra de Odette Barros M ott, que assina uma série literária que inicia com Justino, o retirante (1970) e se encerra com As empregadas (1981), sendo nove livros escritos para que a juventude tomasse contato com os problemas sociais dos jovens de outras regiões brasileiras (GÓES, 1991, p. 155). É nesse contexto que se insere o livro de imagens Cena de Rua, publicado em 1994, por Ângela Lago. 


\section{Efeitos de Sentido Construídos pelo Projeto Gráfico e pelas técnicas de COM POSIÇÃO}

As quatro capas, a página de rosto e as duas orelhas (interna e externamente) são totalmente pretas. 0 detalhe é que o título da obra, o nome da autora e o nome da editora estão dispostos na parte central da primeira capa e da página de rosto, de modo a sugerir que são tipos pichados em algum muro no meio da escuridão de uma grande cidade. Todas as molduras das ilustrações internas também são pretas, ajudando a construir o ambiente soturno da história que se passa à noite.

Quanto à composição das imagens, Dondis $(2004$, p. 139) nos mostra que as técnicas visuais oferecem uma grande variedade de meios para a expressão visual, que se apresentam como polaridades de um continuum. Alerta para 0 fato de que tais técnicas visuais não são opções que se excluem mutuamente e que também são combináveis e interatuantes na utilização compositiva (DONDIS, 2004, p. 139-140), apresentando, assim, algumas categorias, a saber: equilíbrio e instabilidade; simetria e assimetria; regularidade e irregularidade; simplicidade e complexidade; unidade e fragmentação; minimização e exagero; atividade e estase; neutralidade e ênfase; transparência e opacidade; exatidão e distorção, agudeza e difusão.

Se observarmos todas as onze imagens de Cena de rua, depreenderemos que o estilo da obra é o resultado de uma composição forte, pois as técnicas que mais se destacam aparecem de maneira bem polarizada, o que também contribui com a clareza do resultado das imagens.

Comecemos por destacar que a instabilidade é a técnica predominante no livro, sendo sete imagens instáveis contra quatro em equilíbrio. Por exemplo, na primeira imagem podemos notar que todo o seu peso está concentrado do lado direito, pois a junção dos carros ocorre de modo tão harmonioso que eles passam a ser vistos como um só fundo verde fragmentado ${ }^{3}$, ao passo que o menino e o motorista (à direita) são o foco da imagem. E isso ocorre também na terceira, da sexta à nona e na décima primeira imagem, alterando-se os elementos que compõem o fundo.

Outra técnica bem recorrente em Cena de rua é a da distorção, que, ao contrário da exatidão, "adultera o realismo, procurando controlar seus efeitos através do desvio da forma regular" (DONDIS, 2004, p. 154). Retomando a

3 Dondis, ao explicar a diferença entre unidade e fragmentação, diz que "a junção de muitas unidades deve harmonizar-se de modo tão completo que passe a ser vista e considerada como uma única coisa" (DONDIS, 2004, p. 145).

A Cor das Letras - UEFS, n. 9, 2008 
primeira imagem, o movimento ${ }^{4}$ é dado ao menino por meio da distorção, pois os seus membros inferiores não seguem a mesma direção que os seus membros superiores e o seu pescoço, que - por sua vez - parece deslocado do tronco. $E$, igualmente, o motorista tem seus traços fisionômicos distorcidos: 0 nariz, o queixo, os olhos, a sobrancelha e os fios de cabelo são pontiagudos. Essa distorção é recorrente em todas as imagens, acentuando-se na terceira imagem, em que a motorista é representada com um longuíssimo pescoço, além de cabelo, nariz, olhos e dentes pontiagudos.

Ao contrário da regularidade, que constitui o favorecimento da uniformidade dos elementos e o desenvolvimento de uma ordem baseada em algum princípio ou método constante e invariável, a irregularidade enfatiza o inesperado e o insólito (DONDIS, 2004, p. 143) e é outra técnica que aparece em Cena de rua. A quarta e a quinta imagem apresentam ambas duas figuras, sendo uma figura com força direcional diagonal (o menino) e outra figura com força direcional vertical (a senhora; a mãe com o bebê). Diferentemente das demais imagens, que apresentam figuras com força direcional horizontal ou vertical. Ressaltamos essa irregularidade, porque a direção diagonal representa a força direcional mais instável e provocadora das formulações visuais (DONDIS, 2004, p. 60).

Em síntese, as técnicas visuais mais recorrentes nas imagens que compõem Cena de rua são a instabilidade, a distorção, a irregularidade e a atividade. E a combinação dessas técnicas de composição produz imagens com grande força tensiva. Por fim, é preciso dizer que, se ainda não tratamos das cores, é por que preferimos explorar esse recurso ao lado do percurso narrativo no item seguinte.

\section{Análise Semiótica do TeXto Visual Cena de Rua}

Até este momento, expusemos apenas os dados referentes ao contexto sócio-histórico da obra e ao seu plano da expressão. Passaremos, então, a tratar da construção do sentido desse texto visual, examinando elementos concernentes ao seu plano do conteúdo, que é concebido pela Semiótica sob a forma do chamado percurso gerativo do sentido. Trata-se de um percurso que consiste num simulacro metodológico e que vai do mais simples e abstrato ao mais complexo e concreto, apresentando-se em três níveis, a saber:

- o nível fundamental é o mais simples e abstrato e nele se investigam as oposições semânticas que essencialmente sustentam o sentido do

4 A atividade como técnica visual deve refletir o movimento através da representação ou da sugestão (DONDIS, 2004, p. 149). 
texto, tais como liberdade vs. opressão, civilização vs. natureza, vida vs. morte;

- o nível narrativo é caracterizado pela organização da narrativa por um sujeito, que assume os elementos das oposições semânticas fundamentais como valores e os faz circular entre outros sujeitos;

- o nível discursivo é assinalado pela assunção da narrativa pelo sujeito da enunciação, aquele que é responsável pela manifestação do enunciado, e não aquela figura que narra a seqüência dos acontecimentos.

Em Cena de rua, podemos observar não só o percurso narrativo do sujeito menino, como também o percurso narrativo do anti-sujeito motoristas. 0 objeto que circula entre esses sujeitos é representado pela figura das esferas vermelha, amarela e verde que estão dentro de uma caixa retangular. No entanto, esse objeto não se reduz em si mesmo, ele é investido de um valor. Ao depreendermos a cena de um menino que tenta mascatear sua mercadoria nos faróis de trânsito (sinal, sinaleira, semáforo), inferimos que o sujeito menino deve fazer circular tais objetos a fim de garantir sua sobrevivência. É dessa maneira que esse objeto mercadoria é investido do valor sobrevivência, o que nos permite definir vida vs. morte como a oposição semântica fundamental que sustenta o sentido desse texto visual, em que sujeito menino e anti-sujeito motoristas tentam - cada qual à sua maneira - sobreviver no trânsito. Nessa perspectiva, Greimas (1979) explica que:

0 conto maravilhoso não é apenas a história do herói e de sua busca, mas também, de forma mais ou menos oculta, a do vilão: dois percursos narrativos, o do sujeito e 0 do anti-sujeito, desenrolam-se em duas direções opostas, mas caracterizadas pelo fato de que os dois sujeitos visam a um único e mesmo objetovalor (GREIM AS, 1979, p. 299).

Proporemos, então, a leitura do percurso narrativo do sujeito menino, observando também os efeitos obtidos pelo recurso técnico visual das cores, que, em Cena de rua, não servem somente para colorir a cútis das personagens e a lataria dos automóveis.

Nesse livro, as cores travam um diálogo fundamental com um código internacionalmente compartilhado pela cultura do automóvel, pois, em todo 0 mundo, as cores do semáforo têm o mesmo significado e devem cumprir a mesma função de controlar o fluxo de trânsito dos veículos e o dos pedestres também. No entanto, é interessante notar que, do ponto de vista semiótico, essas cores figurativizam o estado juntivo do sujeito menino em relação ao seu objeto de valor. Expliquemos: o sujeito menino deve fazer circular o objeto 
esfera para entrar em conjunção com o valor sobrevivência (dinheiro, alimentação etc.).

Para estabelecimento das relações semióticas entre as cores do semáforo e os estados juntivos do sujeito menino, formulamos o seguinte quadro:

\begin{tabular}{|c|c|c|c|c|}
\hline \multicolumn{5}{|c|}{$\begin{array}{l}\text { Quadro } 1 \text { - Relações semióticas entre as cores do semáforo e os estados juntivos do sujeito } \\
\text { menino }\end{array}$} \\
\hline Cor & $\begin{array}{l}\text { Significado no } \\
\text { trânsito }\end{array}$ & $\begin{array}{l}\text { Significado no } \\
\text { texto }\end{array}$ & $\begin{array}{l}\text { Relação entre } \\
\text { sujeito e objeto }\end{array}$ & Categoria tímica \\
\hline verde & siga & $\begin{array}{l}\text { esperança } \\
\text { sucesso }\end{array}$ & conjunção & euforia \\
\hline amarelo & $\begin{array}{l}\text { atenção } \\
\text { cuidado }\end{array}$ & $\begin{array}{c}\text { surpresa } \\
\text { preparação }\end{array}$ & $\begin{array}{l}\text { relaxamento de } \\
\text { tensão }\end{array}$ & $\begin{array}{l}\text { não-euforia } \\
\text { não-disforia }\end{array}$ \\
\hline vermelho & pare & $\begin{array}{l}\text { agressão } \\
\text { insucesso }\end{array}$ & disjunção & disforia \\
\hline
\end{tabular}

Devemos notar que a representação cromática do sujeito e do antisujeito estabelece a própria oposição entre eles: o menino é figurativizado pela cor verde, enquanto os motoristas o são pela cor vermelha. Dessa forma, podemos opor os sujeitos em verde vs. vermelho, sujeito vs. anti-sujeito, protagonista e adjuvante vs. antagonistas. Isso, com exceção à quinta imagem, em que a cor azul quebra essa isotopia ao representar a proteção e o carinho dispensados pela mãe ao seu filho. Já a representação cromática dos automóveis é que indica os estados juntivos do menino.

A cor verde está associada aos estados conjuntivos, em que o sujeito menino torna-se sujeito da ação e projeta sua esperança no sucesso (conforme primeira, oitava e décima primeira imagens), corroborando o sentido do verde no semáforo: siga.

A cor amarela está associada aos estados de relaxamento entre conjunção e disjunção. Há aí dois momentos distintos de relaxamento que preparam o sujeito para mudança de estados:

a) na segunda imagem, o amarelo indica que o sujeito menino está sendo preparado para perder seu objeto (sofrer uma falta), o que ocorre na terceira imagem. 0 menino vai percorrendo gradualmente um percurso narrativo disfórico, pois está mascateando (primeira imagem), surpreende-se com a ameaça dos cães (segunda imagem), é roubado (terceira imagem), deixa de mascatear (quarta e quinta imagens) e liqüida seu objeto (sexta e sétima imagens), liqüidando também sua esperança de sobrevivência;

b) a partir da sétima imagem, a cor amarela indica que o sujeito menino está sendo preparado para obter um novo objeto e retomar 0 
percurso narrativo eufórico, em que se configura no sujeito da ação em busca da sobrevivência. O sujeito menino furta um objeto (oitava imagem), foge da perseguição (nona e décima imagens) e volta a mascatear (décima primeira imagem).

Confirma-se aí o sentido do amarelo no semáforo: atenção.

Finalmente, a cor vermelha está associada aos estados disjuntivos do sujeito menino em relação ao seu objeto: o sujeito do fazer perde seu objeto e torna-se um sujeito de estado. A terceira e a sexta imagens definem o limite desse estado passional do sujeito menino. Na terceira imagem, o menino é roubado, perde seu objeto; na quarta imagem, o menino admira as riquezas da senhora; na quinta imagem, o menino contempla o afeto e o carinho entre mãe e filho; na sexta imagem, a cor vermelha sinaliza o estado disjuntivo, pois o sujeito menino está perdendo (sem fazer circular) seu objeto. Em suma, o menino deixa de realizar sua tarefa (mascatear), porque se torna um sujeito de estado (e não de ação), perfazendo o percurso passional da resignação. Eis que o sentido do vermelho no semáforo se faz presente no percurso narrativo do sujeito: pare.

No que diz respeito ao nível discursivo, aquele em que o enunciador assume a narrativa, podemos dizer que não há eufemismo no tom da autora Ângela Lago, pois o livro discursiviza o tema das crianças que vivem em estado de risco e o descaso da sociedade pelo tema. Uma criança mascateando doces, limpando os parábrisas dos carros, fazendo "flanelinha", pedindo esmolas ou roubando, não comove as pessoas cidadãs no trânsito, ao contrário, incomodaas a ponto de instaurar o sentimento de rivalidade entre esses sujeitos.

A tensão de Cena de rua se expressa não apenas por meio da combinação de suas técnicas visuais, mas também pelos conhecimentos prévios que 0 leitor mobiliza ao re-conhecer a cena do menino de rua, desamparado, que tenta sobreviver abordando motoristas no trânsito. A construção do tempo e do espaço em Cena de rua representa, metonimicamente por meio de uma rua movimentada, uma grande cidade moderna. Trata-se da representação do espaço social, do espaço transformado pelo trabalho do homem através do tempo, revelando os costumes e o caráter dos sujeitos enquanto indivíduos membros de um grupo social e representados por meio de personagens, que são a '[...] 'amplificação' ou 'síntese' de todas as possibilidades de existência permitidas ao do Homem ou à condição humana" (COELHO, 1981, p. 59). A narração da história desse menino deixa emergir um discurso que desvela uma das conseqüências da desigualdade social tão fortemente manifestada nas grandes cidades modernas. 


\section{CONSIDERAÇÕES FINAIS}

Acreditamos que, por meio deste artigo, tenhamos conseguido mostrar que 0 alfabetismo ou letramento visual (bem como o verbal, o digital, o televisivo etc.) não pode se restringir ao (re)conhecimento dos elementos básicos e das técnicas de linguagem empregadas na construção de um objeto simbólico, que é também um objeto cultural e de comunicação, o que faz pressupor a interação entre sujeitos. Nossa análise tentou mostrar como os fatores "internos" de construção do texto relacionam-se com os fatores "externos" ao texto, considerando a importância do contexto sócio-histórico como parte constitutiva da obra, e não como um mero envelope. Se o texto pressupõe um sujeito e está historicamente inserido na sociedade, não temos mais somente o texto, temos também o discurso.

Neste estudo, nos detivemos a um objeto literário pertencente à literatura infanto-juvenil. Poderíamos nos indagar se a temática dessa obra não é propriamente voltada ao público infantil, se sua linguagem não visa ao lúdico, à fantasia, porque é muito realista. Poderíamos, porque "quanto mais o homem cede ao seu lado racional, para relacionar-se de modo útil, linear ou superficial com a exterioridade, mais se distancia do mito, do sonho, da infância e da poesia e da arte em geral" (RESENDE, 1988, p. 111). E, se entendermos a poética realista como este "relacionamento útil e linear com a exterioridade", concluiremos que a linguagem realista não é a mais apropriada à literatura infantil e juvenil, já que a mesma não privilegiaria o elemento infância. No entanto, queremos concluir nossa exposição deixando a seguinte questão: qual foi o elemento subtraído do menino de Cena de rua senão a infância?

\section{REFERÊNCIAS}

BARROS, Diana Luz Pessoa. Teoria semiótica do texto. 4. ed. São Paulo: Ática, 2000.

BRASIL. Secretaria de Educação Fundamental. Parâmetros curriculares nacionais: terceiro e quarto ciclos do ensino fundamental: língua portuguesa. Brasília: MEC/SEF, 1998.

BRASIL. Secretária de Educação Fundamental. Parâmetros curriculares nacionais (Ensino M édio): parte II - linguagens, códigos e suas tecnologias. Brasília: MEC/ SEF, 2000.

CITELLI, Adilson. Educação e mudanças: novos modos de conhecer. In: Idem. (Coord.). Outras linguagens na escola: publicidade, cinema e TV, rádio, jogos, informática. 4. ed. São Paulo: Cortez, 2004.

COELHO, Nelly Novaes. A literatura infantil: história, teoria, análise: das origens orientais ao Brasil de hoje. São Paulo: Quíron; Brasília: INL, 1981.

DONDIS, A. Donis. Sintaxe da linguagem visual. São Paulo: M artins Fontes, 2003.

FIORIN, José Luiz. Linguagem e ideologia. 7. ed. São Paulo: Ática, 2003.

GÓES, Lúcia Pimentel. Introdução à literatura infantil e juvenil. 2. ed. São Paulo: Pioneira, 1991. 
GREIM AS. Algirdas Julien. Dicionário de semiótica. São Paulo: Cultrix, 1979.

LAGO, Angela. Cena de rua. Belo Horizonte: RHJ, 1994.

PETTER, Margarida. Linguagem, língua, lingüística. In: FIORIN, José Luiz. (Org.). Introdução à Lingüística. I - Objetos teóricos. 2. ed. São Paulo: Contexto, 2003, p. 11-24.

RESENDE, Vânia Maria. 0 menino na literatura brasileira. São Paulo: Perspectiva, 1988.

SOARES, M agda. Alfabetização e letramento. 5. ed. São Paulo: Contexto, 2008.

\section{ANEXOS}

Capa do livro

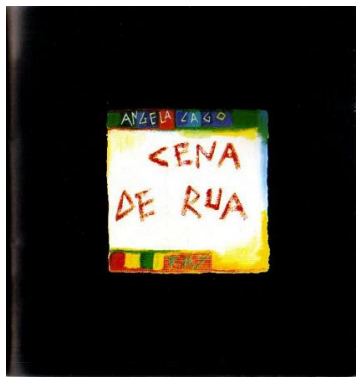

Primeira imagem

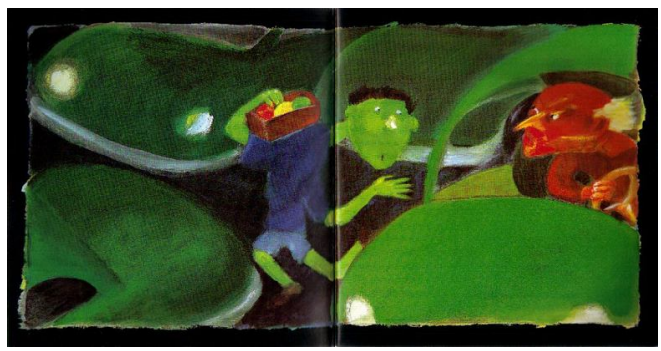

Segunda imagem

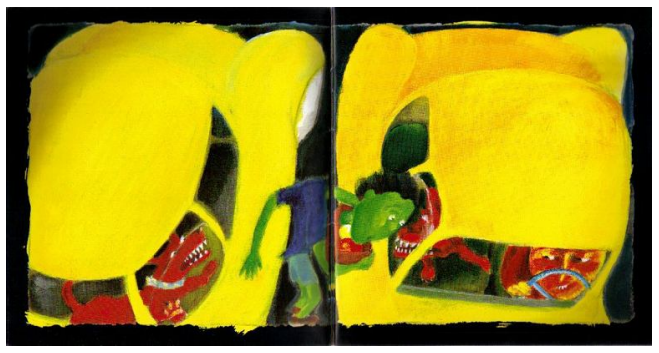




\section{Terceira imagem}

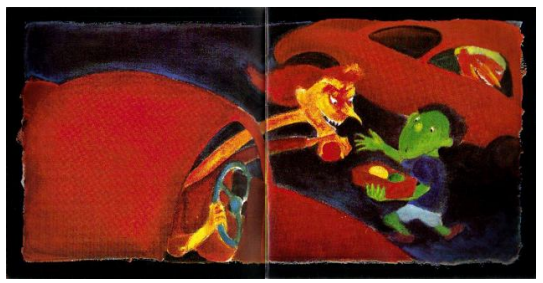

Quarta imagem

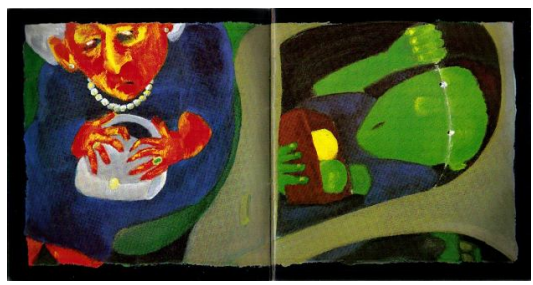

Quinta imagem

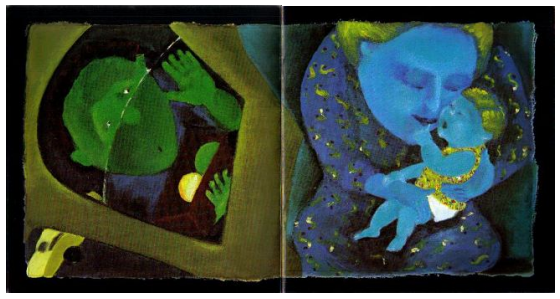

Sexta imagem

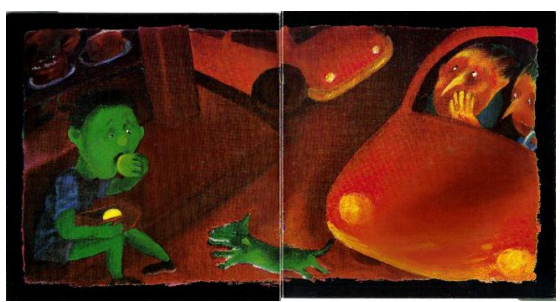


Sétima imagem

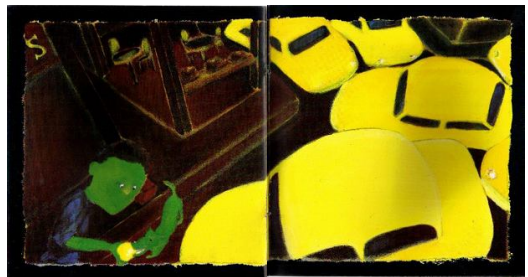

Oitava imagem

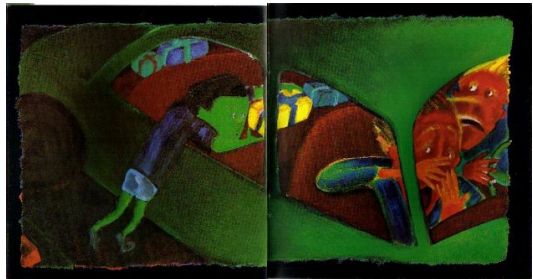

Nona imagem

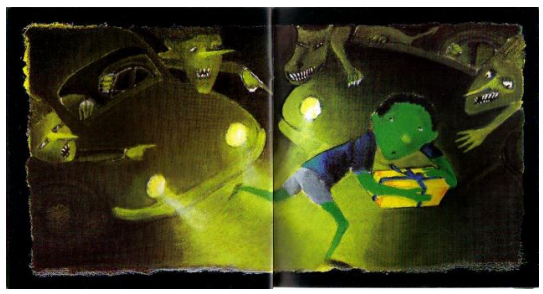

Décima imagem

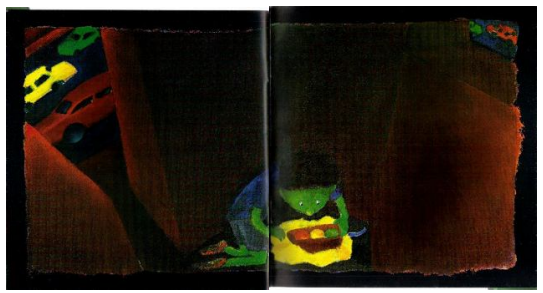

Décima primeira e última imagem

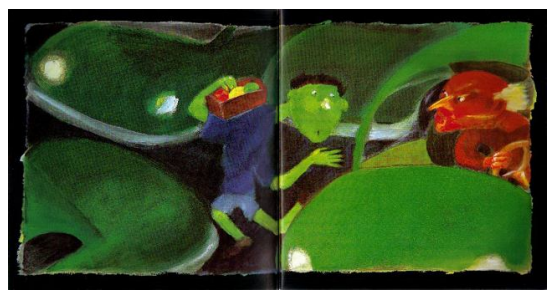

